\title{
GENETIC DIVERSITY ANALYSIS OF BRINJAL (SOLANUM MELONGENA L.) USING RAPD MARKERS
}

\author{
Shetul Muna Parvin \\ Post graduate student \\ Department of Horticulture \\ Bangladesh Agricultural University \\ Mymensingh-2202, Bangladesh
}

\author{
Md. Golam Rabbani \\ Professor \\ Department of Horticulture \\ Bangladesh Agricultural University \\ Mymensingh-2202, Bangladesh
}

\author{
Md. Abu Zafur Al Munsur \\ PhD Fellow, Department of \\ Agronomy, Sher-e-Bangla \\ Agricultural University, Dhaka, \\ Bangladesh. \\ Additional Deputy Director (LR) \\ Department of Agricultural \\ Extension, Khamarbari, Dhaka, \\ Bangladesh.
}

\begin{abstract}
An experiment was conducted at the Horticulture Farm, Department of Horticulture, Bangladesh Agricultural University, Mymensingh to study the variability of 12 selected accessions of brinjal using morphological traits and RAPD. Molecular characterization and diversity study was conducted using RAPD markers. Amplification with 5 decamer primers produced 54 RAPD markers of which $49(89.56 \%)$ were polymorphic and $5(\mathbf{1 0 . 4 4 \% )}$ were monomorphic. The highest genetic distance $(0.9445)$ and the lowest genetic identity (0.3889) were observed in the accessions SM59 vs. SM11 combination. The lowest genetic distance $(\mathbf{0 . 1 3 8 8})$ was observed between the accessions SM22 and SM29 and higher genetic identity was also observed in this combination. Dendrogram was constructed from genetic distance and 12 brinjal accessions fall in five clusters. Thus the RAPD analysis provided an effective method in investigating genetic variation and relatedness in twelve brinjal accessions.
\end{abstract}

Keywords - Brinjal, Genetic diversity, RAPD, Solanum melongena,

\section{INTRODUCTION}

Brinjal (Solanum melongena L.) is an important solanaceous vegetable crop worldwide and also in Bangladesh. It has high nutritional value in respect of calorie, iron, phosphorus and riboflavin contents than tomato [1] (Shaha, 1989). It is the second most important vegetable crop after potato in Bangladesh in respect of total area, and third in respect of production [2].The fruits, leaves, stem and roots of brinjal are widely used in ayurvedic medicine for the patients suffering from diabetes, asthma, tooth ache, cholera, bronchitis and dysentery. Brinjal has potentiality as raw material in pickle making and in dehydration industries [3] (Singh et al., 1963). Due to its high nutritional value, taste, easy cooking quality and year round availability, brinjal has become a widely consumed and popular vegetable in Bangladesh.

Although it is the major native vegetables in our country, very little attention has been given for its improvement and conservation. Among the cultivated varieties, wide range of genetic variability exists which would disappear in course of time. Therefore, those germplasm should be properly evaluated and conserved for future use. Variability is the touch-stone to a breeder to evolve high yielding varieties through selection either from the existing accessions or from the segregates of different crosses. Hence, the genetic information on yield and yield contributing characters need to be properly assessed for its improvement. Also, similarity or duplication of the germplasm should be avoided for mid or long term conservation of the collected germplasm. For rapid and efficient plant breeding program, knowledge of interrelationship among yield and yield contributing characters is also necessary.

Genetic diversity studies based on morphological traits and molecular marker studies enable the evaluation of genetic variation prior to the initiating of a new breeding programme. Molecular markers have appeared to be very useful tools for assessing bio-diversity and revealing differences and relationship between taxa [4] (Dore, 2001). Crop improvement programmme based on phenotypic markers are generally slower than desire, because phenotypic assessment does not always reflect true genotypic performance. Moreover phenotypic markers are affected by environment and may 


\section{International Journal of Engineering Applied Sciences and Technology, 2020 Vol. 5, Issue 3, ISSN No. 2455-2143, Pages 501-505 \\ Published Online July 2020 in IJEAST (http://www.ijeast.com)}

have weak linkage with the target trait(s). Molecular markers like SSR, RFLP, RAPD and AFLP. are being developed and applied to gene banks and plant breeding programs, particularly for the identification of accessions, the detection of genetic relationships and introduction of those markers based on polymerase chain reaction (PCR) technology has led to the development of several novel genetic assays that can be used for many purposes in plant genetic analysis such as cultivar identification, gene mapping and so on. The study was taken to characterize the brinjal germplasm at molecular level through RAPD markers.

\section{MATERIALS AND METHODS}

The experiment was conducted at Horticulture Farm, Vegetable and Fruit Germplasm Laboratory, Department of Horticulture and Central Laboratory, Bangladesh Agricultural University, Mymensingh.

\section{Planting materials used for the experiment}

Twelve brinjal accessions were included in this study for genetic diversity analysis using morphological traits and molecular markers that were collected from different parts of Bangladesh.

\section{Plant genomic DNA isolation}

Genomic samples were extracted from vigorous, young actively growing leaf tissue following modified [5] method. Approximately $0.1 \mathrm{~g}$ of leaf tissues was cut into small pieces and digested by $800 \mu \mathrm{l}$ extraction buffer. The ground sample was vortexed for 20 seconds (IUCHI Automatic Lobo mixture, Japan) and incubated at $65^{\circ} \mathrm{C}$ for $5 \mathrm{~min}$ in hot water bath (JP Selecta $\left.{ }^{(\mathrm{R})}\right)$. The extract was centrifuged for $10 \mathrm{~min}$ at 14000 rpm with a micro centrifuge to allow precipitation of the cell debris. The upper aqueous phase of about $600 \mu \mathrm{l}$ was transferred to another eppendorf tube. For purification, equal volume $600 \mu \mathrm{l}$ of Phenol: Chloroform: Isoamyl alcohol (v: v: $\mathrm{v}=25$ : 24: 1) was added to the tube and vortexed for few seconds. The upper aqueous phase was recovered and DNA was precipitated with $800 \mu \mathrm{l}$ of absolute ethanol (100\%). At this point, DNA became visible as white strands by flicking the tube several times with fingers. DNA was pelleted by centrifugation for $3 \mathrm{~min}$ at $14000 \mathrm{rpm}$. Then the liquid was discarded completely and re-precipitation of the DNA solution was done by adding $400 \mu \mathrm{l}$ of $70 \%$ ethanol with $20 \mu \mathrm{l} 3 \mathrm{M}$ sodium acetate and pelleted by centrifugation for $3 \mathrm{~min}$ at $14000 \mathrm{rpm}$. The liquid was removed completely by pouring and blotting the open tube end on fresh tissue paper. The pellets were then air dried and dissolved in an appropriate volume $(20 \mu 1-50 \mu \mathrm{l})$ of TE buffer, $\mathrm{pH}$ 8.0. Finally, the DNA samples were stored at $-20^{\circ} \mathrm{C}$. Isolated DNA prepared by above protocol often contains a large amount of RNA and pigments that can usually cause spuriously high estimation of DNA concentration on a spectrophotometer. For this $1.8 \%$ agarose gel was used for assessing both the quantity of the genomic DNA.

\section{Selection of primers}

A final subset of five primers out of total of twenty decamer primers (Operon Technologies, Inc., Alameda, California,
USA) exhibiting better quality banding patterns was selected for the analysis of whole sample set of the 12 accessions of brinjal (Table 1). To confirm the reproducibility of RAPD markers, the selected five primers were screened three times on the same samples. It is best to do a series of RAPD reactions using a couple of primers and a set of serial dilutions of each genomic DNA identify empirically the useful range of DNA concentrations, for which reproducible RAPD patterns were obtained.

Table 1. Parameters of the operon random primers used for brinjal accessions

\begin{tabular}{ccc}
\hline Primer code & Sequences $\left(5^{\prime}-3^{\prime}\right)$ & $(\mathrm{G}+\mathrm{C}) \%$ \\
\hline OPA-04 & AATCGGGCTG & 60 \\
OPC-05 & GATGACCGCC & 70 \\
OPC-06 & GAACGGACTA & 60 \\
OPL-05 & ACGCAGGCAC & 60 \\
OPL-07 & AGGCGGGAAC & 70 \\
\hline
\end{tabular}

\section{PCR amplification for RAPD}

The amplification of PCR conditions was based on with some modifications [6]. PCR reactions were performed on each DNA sample in a $10 \mu \mathrm{l}$ reaction mix containing $1 \mu \mathrm{l}$ of $10 \times$ Ampli Taq polymerase buffer, $0.25 \mu \mathrm{l}$ of $10 \mu \mathrm{M}$ primer, $1 \mu \mathrm{l}$ of $250 \mu \mathrm{M}$ dNTPs, 1 unit of Ampli Taq DNA polymerase (Bangalore Genei, India) and $4 \mu \mathrm{l}(100 \mathrm{ng})$ of genomic DNA and suitable amount of sterile deionized water. The PCR was performed in an oil-free thermal cycler (Master Cycler Gradient, Eppendorf). The reaction mix was preheated at $94^{\circ} \mathrm{C}$ for 3 minutes followed by 40 cycles consisted of $1 \mathrm{~min}$ denaturation at $94^{\circ} \mathrm{C}, 1 \mathrm{~min}$ at $34^{\circ} \mathrm{C}$ for annealing and $2 \mathrm{~min}$ at $72^{\circ} \mathrm{C}$ for elongation or extension. After the last cycle, a final step of $7 \mathrm{~min}$ at $72^{\circ} \mathrm{C}$ was added to allow complete extension of all amplified fragments of DNA.

The amplified product from each sample was separated electrophoretically on $1.8 \%$ agarose gel containing $6-\mu 1$ ethidium bromide in $1 \mathrm{X}$ TBE buffer at $100 \mathrm{~V}$ for 60 minutes. Loading dye $(2.0 \mu \mathrm{l})$ was added to the PCR products and loaded in the wells. Two molecular weight marker PUC and 100 bp DNA ladder were also loaded on either side of the gel. Under Ultra Violet (UV) light on a transilluminator RAPD bands were observed and documented by taking photograph using a Gel Cam Polaroid camera.

RAPD data analysis: All distinct bands or fragments (RAPD markers) were thereby given identification numbers according to their position on gel and scored visually on the basis of their presence (1) or absence (0), separately for each individual and each primer. The scores obtained using all primers in the RAPD analysis were then pooled to create -a single data matrix. This was used to estimate polymorphic loci [7] (Nei's, 1973), gene diversity, population differentiation $\left(\mathrm{G}_{\mathrm{st}}\right)$, gene flow $\left(\mathrm{N}_{\mathrm{m}}\right)$, genetic distance (D) and to construct a UPGMA dendrogram among populations using a computer program, POPGENE (Version 1.31) [8] (Yeh et al., 1999). The similarity index values (SI) between the RAPD profiles of any two individuals on the same gel were calculated from RAPD markers according to the this formula: Similarity index (SI) = $2 N_{x y} / N_{x}+N_{y}$ Where, $N_{x y}$ is the total number of RAPD bands 
shared by individuals $\mathrm{x}$ and $\mathrm{y}$ respectively, and $\mathrm{Nx}$ and $\mathrm{N}_{\mathrm{y}}$ are the number of bands in individual $\mathrm{x}$ and $\mathrm{y}$, respectively [9] (Chapco et al., 1992). The SI value range from 0 to 1 . When $\mathrm{SI}=1.0$, the two DNA profiles are identical and when SI is 0.0, there are no common bands between the two profiles. Within population similarity $\left(\mathrm{S}_{\mathrm{i}}\right)$ was calculated as the average of SI across all possible comparisons between individuals within a population. Between population similarity $\left(S_{\mathrm{ij}}\right)$ was calculated as the average similarity between each paired individuals of population i and j [10] (Lynch, 1991).

\section{EXPERIMENT AND RESULT}

\section{Primer selection and RAPD pattern}

Among the 20 primers initially tested, five decamer primers (OPA-4, OPC-5, OPC-6, OPL-5, and OPL-7) were used in RAPD analysis of twelve brinjal accessions. These primers yielded comparatively maximum number of amplification products with high intensity with minimal smearing, good resolution and also clear bands. The number of fragments amplified per primer varied. The five primers generated 54 distinct bands with size ranging from 140-1500 bp, of which $49(89.56 \%)$ were considered as polymorphic and 5 bands $(10.44 \%)$ were monomorphic amongst the 12 brinjal accessions. Among the 5 primers, OPC-5 and OPC-6 produced maximum number of polymorphic bands (12) that indicated a high level of polymorphism and other primers OPA-4, OPL-7 and OPL-5 produced 10, 8 and 7 respectively (Table 2).

Table 2: RAPD primers with corresponding bands score and their size range together with polymorphic bands observed in 12 brinjal accessions

\begin{tabular}{ccccc}
\hline $\begin{array}{c}\text { Primer } \\
\text { codes }\end{array}$ & $\begin{array}{c}\text { Total } \\
\text { number } \\
\text { of bands } \\
\text { scored }\end{array}$ & $\begin{array}{c}\text { Size } \\
\text { ranges } \\
\text { (bp) }\end{array}$ & $\begin{array}{c}\text { Number of } \\
\text { polymorphic } \\
\text { bands }\end{array}$ & $\begin{array}{c}\text { Proportion of } \\
\text { polymorphic } \\
\text { loci }(\%)\end{array}$ \\
\hline OPA-04 & 11 & $350-1400$ & 10 & 90.00 \\
OPC-05 & 13 & $140-1500$ & 12 & 90.31 \\
OPC-06 & 12 & $250-1440$ & 12 & 100 \\
OPL-05 & 8 & $250-1500$ & 7 & 87.50 \\
OPL-07 & 10 & $175-1440$ & 8 & 80 \\
\hline Total & 54 & & 49 & 447.81 \\
Average & 10.8 & & 9.8 & 89.562 \\
\hline
\end{tabular}

The level of polymorphism $(89.56 \%)$ indicates the effectiveness of RAPD technique to detect substantial amount of polymorphism or diversity among different accessions of brinjal. The banding patterns of 12 brinjal accessions using primers OPA-4, OPC-5, OPC-6, OPL-7 and OPL-7 are shown in plate 2-6.

Plate 1. RAPD profiles of 12 brinjal accessions using primer OPC-06. M: Molecular weight marker (100 bp DNA ladder in left side and pUC in right side).

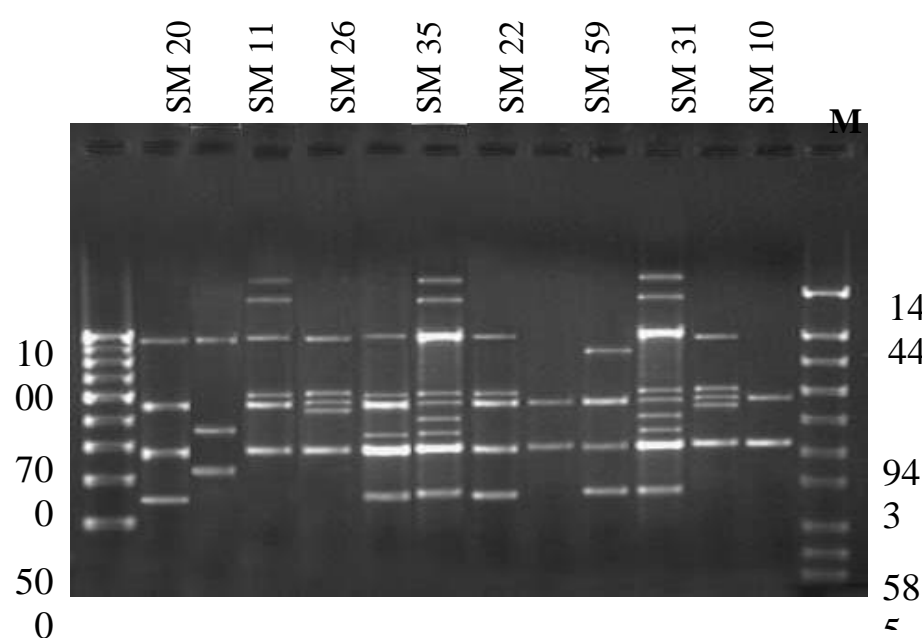

Plate 2. RAPD profiles of 12 brinjal accessions using primer OPL-05. M: Molecular weight marker (100 bp DNA ladder in left side and pUC in right side).

$$
\sum_{n} \sum_{n} \sum_{i} \sum_{n}^{n} \sum_{n}^{n} \sum_{n}^{n} \sum_{n}^{n} \frac{i}{i}
$$

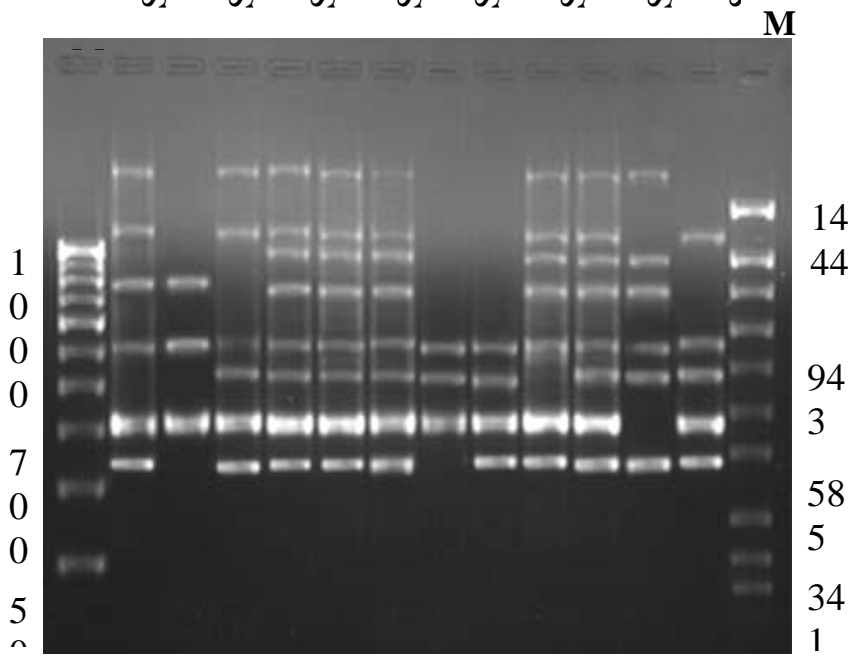

\section{Frequency of polymorphic loci}

The DNA polymorphisms were detected according to the presence and absence of band. Absence of band may be caused by failure of primer to anneal a site in some individuals due to nucleotide sequences difference or by insertions or deletions between primer sites [11] (Clark and Lanigan, 1993). Frequencies of maximum number of polymorphic loci were found to be high with the exception of OPC06-4 (0.0833) and no frequencies were found in OPA04-7 (0.000) and OPL05-5 (0.0000) (Table 3). 
International Journal of Engineering Applied Sciences and Technology, 2020

Vol. 5, Issue 3, ISSN No. 2455-2143, Pages 501-505

Published Online July 2020 in IJEAST (http://www.ijeast.com)

Table 3: Frequencies of polymorphic RAPD markers in 12 brinjal accessions

\begin{tabular}{cccc}
\hline $\begin{array}{c}\text { RAPD } \\
\text { Markers }\end{array}$ & $\begin{array}{c}\text { Gene } \\
\text { frequency }\end{array}$ & $\begin{array}{c}\text { RAPD } \\
\text { Markers }\end{array}$ & $\begin{array}{c}\text { Gene } \\
\text { frequency }\end{array}$ \\
\hline OPA04-1 & 0.1667 & OPC06-4 & 0.0833 \\
OPA04-2 & 0.5000 & OPC06-5 & 0.5833 \\
OPA04-3 & 0.7500 & OPC06-6 & 0.9167 \\
OPA04-4 & 0.8333 & OPC06-7 & 0.1667 \\
OPA04-5 & 0.5000 & OPC06-8 & 0.1667 \\
OPA04-6 & 0.5000 & OPC06-9 & 0.3333 \\
OPA04-7 & 0.0000 & OPC06-10 & 0.9167 \\
OPA04-8 & 0.2500 & OPC06-11 & 0.0833 \\
OPA04-9 & 0.5833 & OPC06-12 & 0.5000 \\
OPA04-10 & 0.6667 & OPL05-1 & 0.6667 \\
OPA04-11 & 0.2500 & OPL05-2 & 0.6667 \\
OPC05-1 & 0.5833 & OPL05-3 & 0.5000 \\
OPC05-2 & 0.2500 & OPL05-4 & 0.6667 \\
OPC05-3 & 0.5833 & OPL05-5 & 0.0000 \\
OPC05-4 & 0.5000 & OPL05-6 & 0.7500 \\
OPC05-5 & 0.6667 & OPL05-7 & 0.9167 \\
OPC05-6 & 0.1667 & OPL05-8 & 0.8333 \\
OPC05-7 & 0.5833 & OPL07-1 & 0.5833 \\
OPC05-8 & 0.0000 & OPL07-2 & 0.5833 \\
OPC05-9 & 0.6667 & OPL07-3 & 0.9167 \\
OPC05-10 & 0.6667 & OPL07-4 & 0.1667 \\
OPC05-11 & 0.5000 & OPL07-5 & 0.9167 \\
OPC05-12 & 0.4167 & OPL07-6 & 0.4167 \\
OPC05-13 & 0.8333 & OPL07-7 & 0.5000 \\
OPC06-1 & 0.2500 & OPL07-8 & 0.0000 \\
OPC06-2 & 0.2500 & OPL07-9 & 0.0000 \\
OPC06-3 & 0.7500 & OPL07-10 & 0.3333 \\
\hline & & & \\
\hline
\end{tabular}

\section{Genetic variation}

The estimate of [7] Nei's (1973) genetic diversity for entire accessions of brinjal was 0.36 and Shannon's information index was 0.54 . There was a high level of genetic variation among the studied accessions of brinjal from the proportion of polymorphic loci point of view (Table 4).

Table 4: Summary of genetic diversity statistics for all loci in 12 brinjal accessions

\begin{tabular}{cccccc}
\hline Loci & $\begin{array}{c}\text { Gene } \\
\text { diversity } \\
(\mathrm{h})\end{array}$ & $\begin{array}{c}\text { Shanon } \\
\text { information } \\
\text { index (i) }\end{array}$ & Loci & $\begin{array}{c}\text { Gene } \\
\text { diversity } \\
(\mathrm{h})\end{array}$ & $\begin{array}{c}\text { Shanon } \\
\text { information } \\
\text { index (i) }\end{array}$ \\
\hline OPA04-1 & 0.2778 & 0.4506 & OPC06-4 & 0.1528 & 0.2868 \\
OPA04-2 & 0.5000 & 0.6931 & OPC06-5 & 0.4861 & 0.6792 \\
OPA04-3 & 0.3750 & 0.5623 & OPC06-6 & 0.1528 & 0.2868 \\
OPA04-4 & 0.2778 & 0.4506 & OPC06-7 & 0.2778 & 0.4506 \\
OPA04-5 & 0.5000 & 0.6931 & OPC06-8 & 0.2778 & 0.4506 \\
OPA04-6 & 0.5000 & 0.6931 & OPC06-9 & 0.4444 & 0.6365 \\
OPA04-7 & 0.0000 & 0.0000 & OPC06-10 & 0.1528 & 0.2868 \\
OPA04-8 & 0.3750 & 0.5623 & OPC06-11 & 0.1528 & 0.2868 \\
OPA04-9 & 0.4861 & 0.6792 & OPC06-12 & 0.5000 & 0.6931 \\
OPA04-10 & 0.4444 & 0.6365 & OPL05-1 & 0.4444 & 0.6365 \\
OPA04-11 & 0.3750 & 0.5623 & OPL05-2 & 0.4444 & 0.6365 \\
OPC05-1 & 0.4861 & 0.6792 & OPL05-3 & 0.5000 & 0.6931 \\
OPC05-2 & 0.3750 & 0.5623 & OPL05-4 & 0.4444 & 0.6365 \\
OPC05-3 & 0.4861 & 0.6792 & OPL05-5 & 0.0000 & 0.0000 \\
OPC05-4 & 0.5000 & 0.6931 & OPL05-6 & 0.3750 & 0.5623 \\
OPC05-5 & 0.4444 & 0.6365 & OPL05-7 & 0.1528 & 0.2868 \\
OPC05-6 & 0.2778 & 0.4506 & OPL05-8 & 0.2778 & 0.4506 \\
OPC05-7 & 0.4861 & 0.6792 & OPL07-1 & 0.4861 & 0.6792 \\
OPC05-8 & 0.0000 & 0.0000 & OPL07-2 & 0.4861 & 0.6792 \\
OPC05-9 & 0.4444 & 0.6365 & OPL07-3 & 0.1528 & 0.2868 \\
OPC05-10 & 0.4444 & 0.6365 & OPL07-4 & 0.2778 & 0.4506 \\
OPC05-11 & 0.5000 & 0.6931 & OPL07-5 & 0.1528 & 0.2868 \\
& & & & &
\end{tabular}

\begin{tabular}{cccccc} 
OPC05-12 & 0.4861 & 0.6792 & OPL07-6 & 0.4861 & 0.6792 \\
OPC05-13 & 0.2778 & 0.4506 & OPL07-7 & 0.5000 & 0.6931 \\
OPC06-1 & 0.3750 & 0.5623 & OPL07-8 & 0.0000 & 0.0000 \\
OPC06-2 & 0.3750 & 0.5623 & OPL07-9 & 0.0000 & 0.0000 \\
OPC06-3 & 0.3750 & 0.5623 & OPL07-10 & 0.4444 & 0.6365 \\
\hline Mean & & & & 0.3457 & 0.5092 \\
Standard & & & & 0.1600 & 0.2114 \\
deviation & & & & & \\
\hline
\end{tabular}

\section{Genetic distance and genetic identity}

Pair-wise comparisons of [12] Nei's (1972) genetic distance (GD) between brinjal accessions were computed from combined data for the five primers and the values ranged from 0.1388 to 0.9445 (Table 6 ). Comparatively higher genetic distance was observed between SM59 vs. SM11 (0.9445) while the lowest genetic distance 0.1388 was observed between the accessions SM 22 and SM29. SM35 vs. SM11 and SM44 vs. SM11 (0.8535) accession pairs than other accession combinations. Considering the genetic distance values the results indicate that some accessions of brinjal are genetically different from each other and some are tend to be similar. Genetic identity between varieties was found for the 5 primers, ranged from 0.3889 to 0.8704 . The highest genetic identity (0.8704) was found in SM22 vs. SM29. The lowest (0.3889) was observed between SM11 vs. SM59 (Table 5).

Table 5. Summary of [12] genetic identity (above diagonal) and genetic distance (below diagonal) values between 12 brinjal germplasm

\begin{tabular}{cccccccccccccc} 
& & & & & & & & & & & & & \\
Genotypes & SM 20 & SM 11 & SM 26 & SM 35 & SM 22 & SM 59 & SM 31 & SM 10 & SM 44 & SM 29 & SM 09 & SM 14 \\
\hline SM 20 & $* * * *$ & 0.592 & 0.851 & 0.611 & 0.648 & 0.537 & 0.703 & 0.592 & 0.648 & 0.5926 & 0.722 & 0.611 \\
SM 11 & 0.523 & $* * *$ & 0.518 & 0.425 & 0.500 & $\mathbf{0 . 3 8 8}$ & 0.481 & 0.481 & 0.425 & 0.4444 & 0.500 & 0.537 \\
SM 26 & 0.160 & 0.656 & $* * * *$ & 0.611 & 0.611 & 0.537 & 0.666 & 0.555 & 0.537 & 0.5926 & 0.685 & 0.611 \\
SM 35 & 0.492 & 0.853 & 0.492 & $* * *$ & 0.740 & 0.703 & 0.648 & 0.759 & 0.703 & 0.7222 & 0.666 & 0.703 \\
SM 22 & 0.433 & 0.693 & 0.492 & 0.300 & $* * * *$ & 0.777 & 0.574 & 0.648 & 0.851 & $\mathbf{0 . 8 7 0 4}$ & 0.518 & 0.629 \\
SM 59 & 0.621 & $\mathbf{0 . 9 4 4}$ & 0.621 & 0.351 & 0.251 & $* * * *$ & 0.574 & 0.648 & 0.703 & 0.8333 & 0.518 & 0.629 \\
SM 31 & 0.351 & 0.730 & 0.405 & 0.433 & 0.555 & 0.555 & $* * * *$ & 0.740 & 0.537 & 0.5185 & 0.722 & 0.611 \\
SM 10 & 0.523 & 0.730 & 0.587 & 0.275 & 0.433 & 0.433 & 0.300 & $* * * *$ & 0.685 & 0.6296 & 0.611 & 0.833 \\
SM 44 & 0.433 & 0.853 & 0.621 & 0.351 & 0.160 & 0.351 & 0.621 & 0.378 & $* * * *$ & 0.7593 & 0.444 & 0.666 \\
SM 29 & 0.523 & 0.810 & 0.523 & 0.325 & $\mathbf{0 . 1 3 8}$ & 0.182 & 0.656 & 0.462 & 0.275 & $* * * *$ & 0.537 & 0.611 \\
SM 09 & 0.325 & 0.693 & 0.378 & 0.405 & 0.656 & 0.656 & 0.325 & 0.492 & 0.810 & 0.6217 & $* * *$ & 0.555 \\
SM 14 & 0.492 & 0.621 & 0.492 & 0.351 & 0.462 & 0.462 & 0.492 & 0.182 & 0.405 & 0.4925 & 0.587 & $* * * *$ \\
\hline
\end{tabular}

\section{UPGMA dendrogram}

The Unweighted Pair Group Method of Arithmetic Means (UPGMA) dendrogram based on [12] genetic distance was constructed. This measurement indicated the segregation of the 12 accessions of brinjal into 2 main clusters. SM 11 alone formed separate cluster 'A'. Rest 11-brinjal germplasm grouped in cluster 'B' (Fig.1). SM11 belonged to the cluster A. In cluster B, SM20, SM26, SM31 and SM09 formed sub cluster B-I while SM35, SM10, SM14, SM44, SM59, SM22 and SM29 formed sub cluster B-II. Further, the varieties of sub cluster B-II were divided into sub sub-cluster 3 and subsub-cluster 4. SM35, SM 10 and SM 14 formed sub subcluster 3 and SM44, SM59, SM22 and SM29 belonged to sub sub-cluster 4.

Fig.1. Unweighted pair group method of arithmetic mean (UPGMA) dendrogram based on [12] genetic distance, summarizing data on differentiation in 12 brinjal accessions according to RAPD analysis 
International Journal of Engineering Applied Sciences and Technology, 2020

Vol. 5, Issue 3, ISSN No. 2455-2143, Pages 501-505

Published Online July 2020 in IJEAST (http://www.ijeast.com)

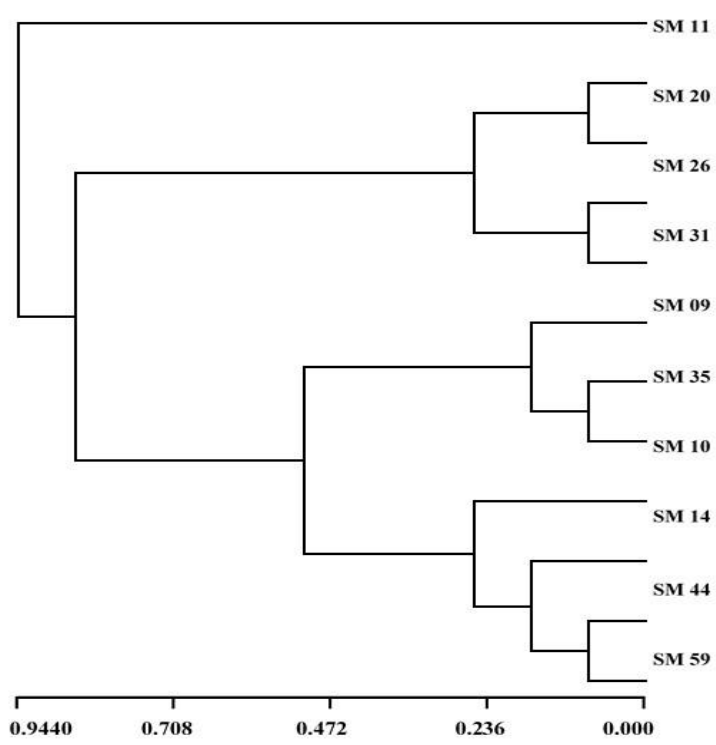

IV. CONCLUSION

RAPD markers produced $89.56 \%$ polymorphic band and the highest genetic distance (0.9445) were observed in the accessions SM59 vs SM11 combination. So, It can be concluded that this cultivar used for further variety development.

\section{REFERENCE}

[1] Shaha MG (1989). Combining ability estimates and Hybrid vigour in eggplant (Solanum melongena). M.Sc. (Ag.) Thesis.Department of Horticulture, BAU, Mymensingh, pp.80-82.

[2] BBS (2008). A pocket book of Agricultural Statistics. Ministry of Agriculture, Bangladesh, pp. 20-21.

[3] Singh S, Krishnamurti S, Katyal SL (1963). Fruit Culture in India, Indian Council of Agricultural Research, New Delhi, pp. 412.

[4] Dore C (2001). Molecular characterization of biodiversity in horticulture. Cometes-rendus-de-I. Academic-d, Agriculture-d-France. 87: 181-191.

[5] Doyle JJ and Doyle JL (1990). A rapid DNA isolation procedure for small quantities of fresh leaf material. Phytochum. Bull. 19: 11-15.

[6] Williams JGK, Kubelik AR, Livak KJ, Rafalski JA and Tingey SV (1990). DNA polymorphisms amplified by arbitrary primers are useful as genetic markers. Nucleic Acids Res. 18: 6531-6535.

[7] Nei M (1973). Analysis of gene diversity in subdivided populations. Proc. Nat. Acad. Sci. USA. 70: 3321-3323.

[8] Yeh F, Yang C, Boyle TBJ, Ye ZH, Mao JX (1999). POPGENE, the user-friendly shareware for population genetic analysis. Molecular Biology and Biotechnology Centre, University of Albetra, Canada.

[9] Chapco W, Ashton NW, Martel RK, Antonishishyn N and Crosby WL (1992). A feasibility study of the use of random amplified polymorphic DNA in the population genetics and systematic of grasshoppers. Genome. 35: 369-574.

[10] Lynch M (1991). Analysis of population genetics structure by DNA fingerprint. In: DNA fingerprinting approaches and applications. Basal, Switzerland, pp. 113-126. [11] Clark AG and Lanigen CMS (1993). Prospects for estimating nucleotide divergence with RAPDs. Mol Evol. 10: 1096-1111.

[12] Nei M (1972). Genetic distance between populations. Am. Nat. 196: 283-292. 